\title{
REAL-TIME CLASSIFICATION OF OBJECTS BY COLOR USING FIELD PROGRAMMABLE GATE ARRAY
}

\section{CLASIFICACIÓN DE OBJETOS POR COLOR EN TIEMPO REAL USANDO ARREGLOS DE COMPUERTAS PROGRAMABLES EN CAMPO}

Manuel Alejandro Tamayo Monsalve', Nubia Liliana Montes Castrillón², Gustavo Adolfo Osorio Londoño ${ }^{3}$.

1 Universidad Nacional de Colombia, Manizales. matamayom@unal.edu.co.

2 Departamento de Sistemas e Informática, Universidad de Caldas, Manizales and Departamento de Ingeniería Eléctrica, Electrónica y Computación, Universidad Nacional de Colombia, Manizales. nubia.montes@ucaldas.edu.co.

3 Departamento de Ingeniería Eléctrica, Electrónica y Computación, Universidad Nacional de Colombia, Manizales.gaosoriol@unal.edu.co.

\section{RESUMEN}

Este artículo presenta un sistema para la clasificación de objetos por color en tiempo real realizada sobre una secuencia de video a 20 cuadros por Segundo (Frames Per Second, FPS). Se utilizó la transformada a coordenadas esféricas (Spherical Coordinate Transform, SCT) para hacer el análisis de color. El histograma para la partición bidimensional en el espacio de color definido por la SCT es calculado en un circuito digital concurrente, logrando la clasificación de cinco colores diferentes. Los resultados mostraron que los colores verde, amarillo y naranja se pueden clasificar de forma confiable. Sin embargo, los colores rojo y magenta se confunden entre sí. La eficiencia del clasificador es de $95.2 \%$. El prototipo se implementó usando una FPGA Cyclone ${ }^{\circledR}$ II 2C70 de Altera en una tarjeta de desarrollo DE2-70 de TERASIC y Quartus II para el diseño..

Palabras claves: SCT, Tiempo real, FPGA, Análisis de color.

\begin{abstract}
:
This paper presents a system for real-time classification by color of objects carried out on a video sequence at 20 Frames Per Second (FPS). The Spherical Coordinate Transform (SCT) is used for the color analysis. The histogram for a partition of a bidimensional color space is computed on a concurrent digital circuit, allowing the classification of five different colors. The results have shown that green, yellow, and orange colors can be reliably classified. However, red and magenta colors are confused each other. The efficiency of the classification is $95.2 \%$. The prototype was implemented using an Altera Cyclone ${ }^{\circledR}$ II 2C70 FPGA device on a DE2-70 educational board from TERASIC and Quartus II for the design.
\end{abstract}

Keywords: SCT, Real time, FPGA, Color analysis. 


\section{INTRODUCTION:}

The Colombian coffee industry has to improve its competitiveness to continue being part of the worldwide market. A way of doing that is by opening new markets with different blends of coffee but keeping its production of high quality coffee. To get to this goal, it is necessary to reduce the production cost without compromising the capability of selecting coffee beans at several maturity stages. That is why an automatic, fast, and economic sorting system for coffee beans is an alternative. Countries like Brazil, Australia, and Hawaii have successfully implemented mechanical harvesting of coffee beans (1). However, these devices do not reach the Colombian coffee quality standard. Designing a coffee beans sorting system to be used after the harvesting, would allow the use of mechanical harvesters and would open markets for different blends.

CENICAFE and Universidad Nacional de Colombia, over 10 years, have been conducting research to improve selectivity in mechanical harvesting devices $(2,3)$ and developing sorting systems $(4-8)$ in order to reduce the production cost. This research has shown that the maturity stage of a coffee bean is highly correlated to the optical properties of the epidermis and its size. Besides, different blends of coffee can be produced by mixing coffee beans at several maturity stages in proper proportions. This will increase the potential of the coffee market and will allow a better use of the raw material.

In (9) artificial vision is shown as one of the most used strategies for quality analysis and sorting of fruits and vegetables. The research in Colombia has followed this worldwide trend. Some studies have been made to the coffee beans sorting problem using digital image processing $(5,6,10)$. However a major challenge is to make them work in real time. Different strategies have been proposed to reduce the processing time of the digital image processing algorithms. Some of these alternatives are multiprocessor systems, graphics processing units and programmable logic devices (i.e. FPGA, CPLD). All these alternatives reduce the processing time by executing parallel operations.

In addition, one work developed at Universidad Nacional de Colombia (11) implemented the Spherical Coordinate Transform (SCT) to perform successful coffee-beans segmentation in images. As a result, it was observed that this transform has a great potential for color analysis too. This work presents the FPGA implementation of the SCT algorithm. This implementation is applied on the sorting of Ping-Pongs of green, red, yellow, orange, magenta, purple, and blue colors (see Fig. 1(a)). The selection of these colors is based on the fact that during the growing process, the epidermis of a coffee bean changes from green color to red color passing through different tones of yellow, orange, and magenta as it is shown in Fig. 1(b). Coffee beans are not used here because the principal goal of this work is to verify a correct implementation of the SCT on FPGA in real time. This is one step in the solution of the coffee beans sorting problem.

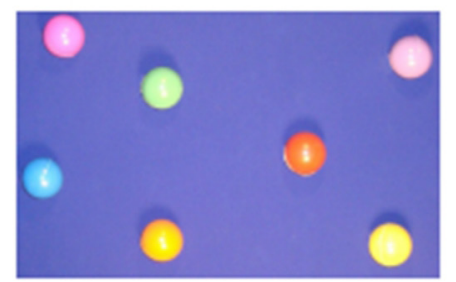

(a)

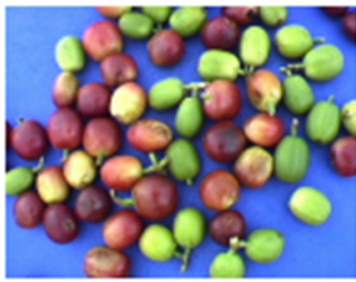

(b)
Figure 1. (a) Ping-Pongs used for the experiment. (b) Real coffee beans

This document is organized as follows. Next section describes the Spherical Coordinate Transform (SCT) as well as the definition of a partition on a two dimensional color space. Furthermore, it presents main aspects on the implementation of a concurrent circuit for classification of five different colors on a FPGA, and it includes a description of the image acquisition setup and most aspects of the experiment. Results and main conclusions are presented in last two sections.
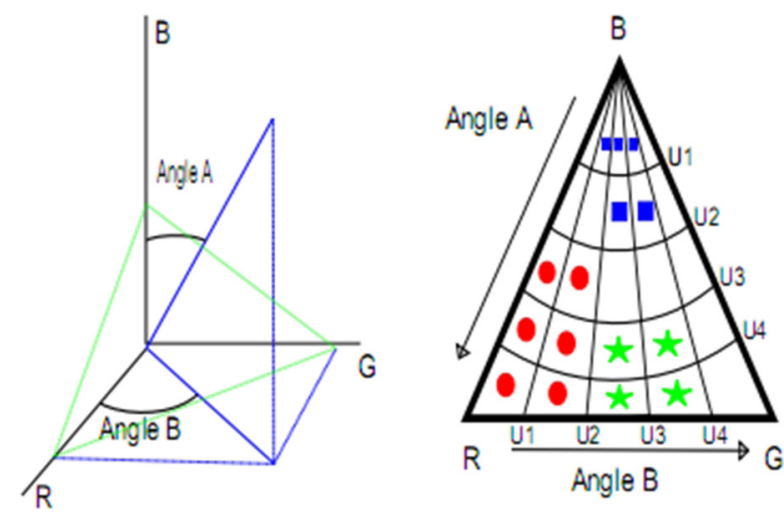

Figure 2. Spherical Coordinate Transform (a) Spherical coordinates (b) SCT Triangle 


\section{MATERIALS AND METHODS}

This section presents the circuit designed for the color classification of objects. The proposed circuit architecture allows every pixel to be processed and classified during one clock cycle. Then there is no need of using memory for the image processing. Following are the algorithm for the color analysis, its implementation on FPGA and the experiment description.

\section{A. Spherical Coordinate Transform (SCT) imple- mentation on FPGA}

Spherical Coordinate Transform (SCT) is a clustering algorithm that tries to decouple the brightness information from the color information. It transforms the RGB color space to a spherical color space as it is shown in Fig. 2 (12). The block division of the SCT triangle is based on the human eye capacity of distinguishing blue tones better than green or red ones (12). The clustering is made on the two-dimensional space defined by the angles $\mathrm{A}$ and $\mathrm{B}$. This space is divided into blocks separated by equal angular values, and after applying the SCT transform to the whole image, the pixels will be grouped according to angles.

In the work developed in (11), five divisions along both angles A and B were found enough to differentiate green, red, and blue tones. The angles range goes from 0 to $\pi / 2$ radians, and then each block is defined by the following thresholds:

$u_{0}=0, u_{1}=\frac{\pi}{10}, u_{2}=\frac{\pi}{5}, u_{3}=\frac{3 \pi}{10}, u_{4}=\frac{2 \pi}{5}, u_{5}=\frac{\pi}{2}$

In Fig. 2(b) can be observed the location of the thresholds and the blocks that cluster red, green, and blue tones represented with circles, stars, and squares respectively. The equations that are used to compute the angles $\mathrm{A}$ and $\mathrm{B}$ are stated below:

$$
\begin{gathered}
A=\arctan \left(\frac{\sqrt{R^{2}+G^{2}}}{B}\right) \\
B=\arctan \left(\frac{G}{R}\right)
\end{gathered}
$$

Equations [2] and [3] are not directly implemented on the FPGA but an equivalent transform as explained in the following paragraphs. Taking into account that the values of $R, G$ and $B$ are immediately available, and that the calculation of the arctangent can be avoided, the angles are not computed but their tangents. Therefore, the thresholds shown in equation [1] are modified:

$$
\widehat{u}_{i}=\tan \left(u_{i}\right)
$$

The five divisions in angle $A$ are now defined by the following ranges:

$$
A_{i}: \widehat{u}_{i-1} \leq \sqrt{\frac{R^{2}+G^{2}}{B^{2}}}<\widehat{u}_{i}
$$

and the ones of the angle $B$, by these ranges:

$$
B_{i}: \widehat{u}_{i-1} \leq \frac{G}{R}<\widehat{u}_{i}
$$

with $i$ in $\{1,2,3,4,5\}$

As a result, when a pixel is read, it is possible to locate it at one of the 25 blocks shown in Fig. 2(b). For example, if a pixel has a $(R, G, B)$ value of $(250,10,5)$, after applying equations [5] and [6], it can be located at the left lower corner of the triangle, since it belongs to $A_{5}$ and $B_{1}$ divisions.

To avoid the time consuming operations of square root and divisions, equations [5] and [6] are rewritten as:

$$
\begin{gathered}
A_{i}: \widehat{u}^{2}{ }_{i-1} B^{2} \leq R^{2}+G^{2}<\widehat{u}_{i}^{2} B^{2} \\
B_{i}: \widehat{u}_{i-1} R \leq G<\widehat{u}_{i} R
\end{gathered}
$$

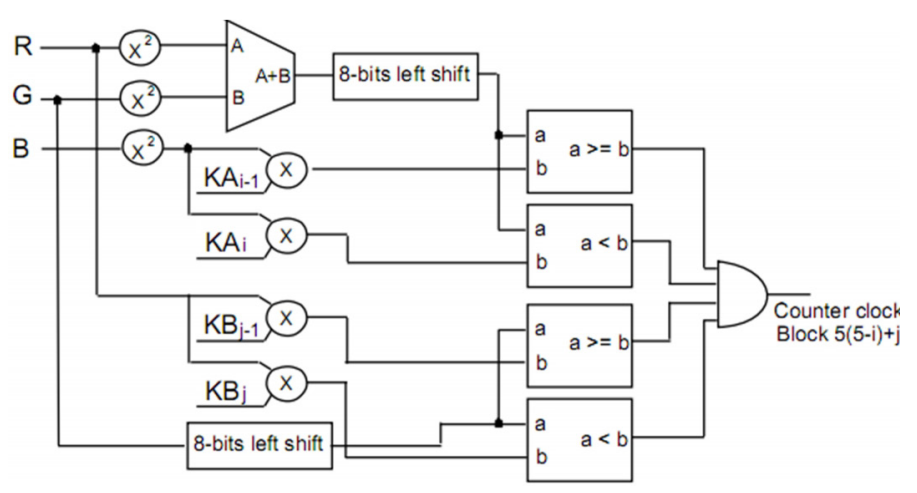

Figure 3. Circuit implemented on the FPGA

Moreover, multiplications and comparisons using floating point representation of equations [7] and [8] are reorganized to work with integers and shifting operations:

$$
\begin{aligned}
& A_{i}: K A_{i-1} B^{2} \leq 256\left(R^{2}+G^{2}\right)<K A_{i} B^{2} \\
& B_{i}: K B_{i-1} R \leq 256 G<K B_{i} R
\end{aligned}
$$


Where the constants $K A_{i}$ and $K B_{i}$ have the following values to approximate the angles tangents:

$$
\begin{aligned}
& K A_{0}=0, K A_{1}=27, K A_{2}=135, \\
& K A_{3}=485, K A_{4}=2425, K A_{5}=\infty \\
& K B_{0}=0, K B_{1}=83, K B_{2}=186, \\
& K B_{3}=352, K B_{4}=788, K B_{5}=\infty
\end{aligned}
$$

The circuit designed for the implementation of the SCT on the FPGA is shown in Fig. 3. The whole system for the color classification of pixels, including the acquisition, the processing and the visualization circuits are shown in Fig. 4. This

Table 1. Color assigned to each block

\begin{tabular}{cccc}
\hline Block & R & Color & $\mathrm{G}$ \\
1 & 4095 & 0 & 0 \\
2 & 4095 & 2184 & 0 \\
3 & 4095 & 4095 & 0 \\
4 & 2184 & 4095 & 0 \\
5 & 0 & 4095 & 0 \\
6 & 4095 & 0 & 2184 \\
7 & 4095 & 2184 & 2184 \\
8 & 4095 & 4095 & 2184 \\
9 & 2184 & 4095 & 2184 \\
10 & 0 & 4095 & 2184 \\
11 & 4095 & 0 & 4095 \\
12 & 4095 & 2184 & 4095 \\
13 & 4095 & 4095 & 4095 \\
14 & 2184 & 4095 & 4095 \\
15 & 0 & 4095 & 4095 \\
16 & 0 & 0 & 4095 \\
\hline
\end{tabular}

figure shows the flow of one pixel data through the system, from the CCD camera until the visualization on the monitor with a color depending on its block classification as shown in Table 1. The maxima counter block finder module computes a histogram of the SCT blocks to be used for the color analysis. It is important to note that the memory is used in this system only for visualization purposes.

\section{B. Experimental Design}

The objects to be classified are Ping-Pongs of green, red, yellow, orange, magenta, purple, and blue colors. Images and videos were taken under controlled illu- mination conditions. A speedotron M90 model lamp, the 5 Megapixel digital camera TRDB-D5M, and the Development Kit DE2-70 from Altera were used. Tests were carried out with different backgrounds, two chamois and two cards with several blue tones. This choice obeys to two main reasons. The first one is the discriminant capacity of the SCT for blue tones. The second one is that in the work developed in (11) it was found that this color gives the best results.

The camera was positioned at $50 \mathrm{~cm}$ from the background and at a height of $80 \mathrm{~cm}$. The background was located on the wall and the lamp was situated beside the camera. Tests were carried out with direct and diffuse illumination.

The diffuser used is bond paper. This acquisition system is shown in Fig. 5.

To choose the background and the illumination that allows the best differentiation between the objects, images of Ping-Pongs of each color attached to the background were taken under different illumination conditions. Subsequently, videos of each Ping-Pong in free fall from a height of $1,25 \mathrm{~m}$ and at a distance from the background of $15 \mathrm{~cm}$ were taken. Since the final application is the sorting of coffee beans, this test is important because of the assumption is that the beans will be falling in a free fall way from a dispenser.

With the aim of sorting the Ping-Pongs by color a histogram of the SCT blocks is computed in each video frame. However, the histogram varies for each frame since the scene is continuously moving. Hence, to avoid this problem, a global histogram is created. This global histogram is constructed by the maxima of each block on the video sequence at 20 FPS of the Ping-Pong fall. This is made because it is assumed that the maxima occur when the object is completely present in the frame.

As can be observed from Fig. 2(b), the $A_{1}$ and $A_{2}$ divisions allow us to differentiate between blue tones that belong to the background. Since that is not significant for the color analysis of the objects, then the threshold $u_{l}$ for the angle $\mathrm{A}$ is eliminated producing the 16-block SCT triangle shown in Fig. 6. Therefore, histograms are calculated using 16 counters, one for each block. 


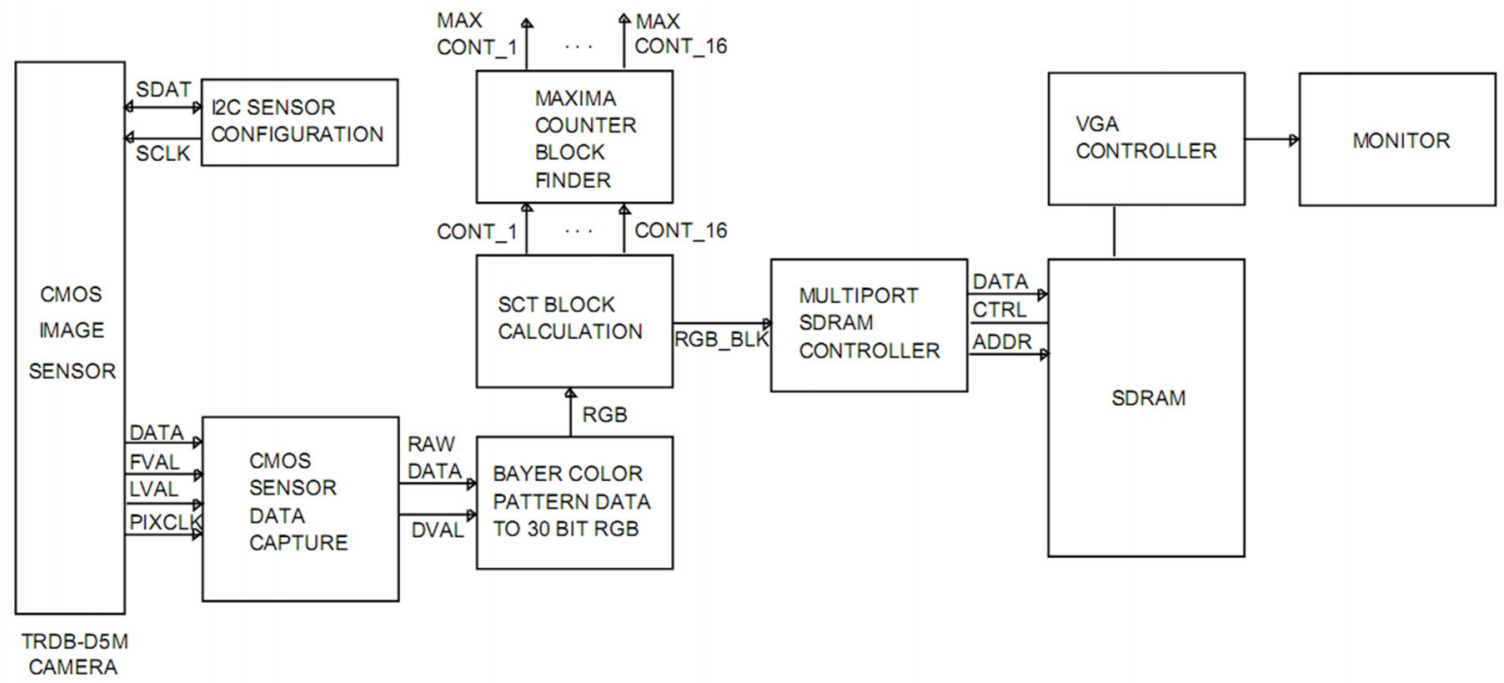

Figure 4: System designed for the color classification of pixels.

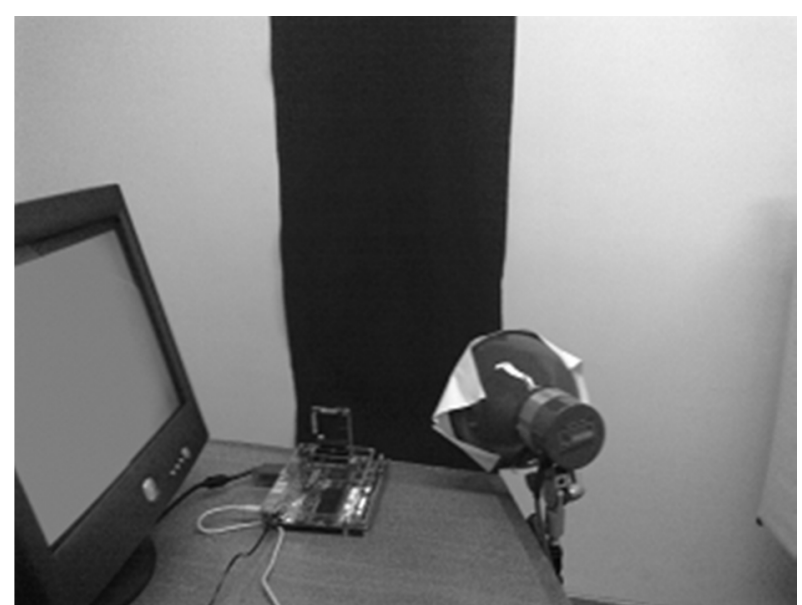

Figure 5: Acquisition System. 5 Megapixel digital camera TRDB-D5M from Altera, DE2-70 educational board from TERASIC with an Altera Cycloneltextregistered II 2C70 FPGA device and speedotron M90 model lamp.

\section{RESULTS AND DISCUSSION}

For each image of the quiet Ping-Pongs the SCT was computed, and the data were analyzed to look for a clear differentiation between the background and the objects. After this analysis, it was concluded that the royal blue chamois gives the best discrimination.

Once the background was chosen, the Ping-Pongs were thrown as explained in the previous section. While the Ping-Pong was falling, histograms were computed as described in the preceding section. The data obtained were analysed and it was found that each color greatly modifies certain blocks of the SCT triangle, showing discriminant capacity (see Table 2). Fig. 7 shows the average of the histograms obtained for 10 Ping-Pongs

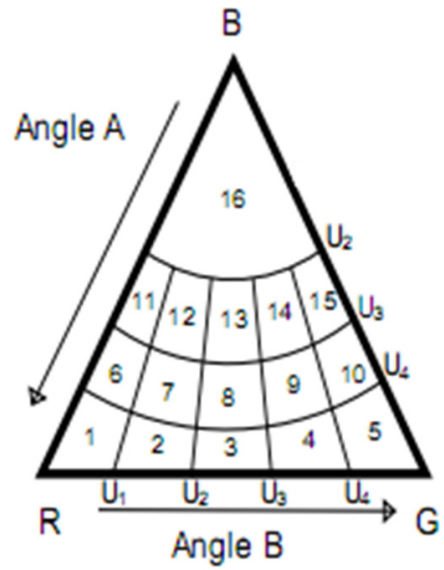

Figure 6: 16-block SCT triangle

of each color.

Purple and blue colors do not appear in the table because they mixed up with the background. Since the final application is the sorting of coffee beans, these colors are excluded from the subsequent tests. This is done based on the fact that these colors are not part of a coffee bean.

After identifying the corresponding blocks to each color, a sorting experiment was carried out. 100 PingPongs were thrown for each color. The global histogram was computed, and the Ping-Pong was classified according to the following decision rules based on the results shown in Table 2. 


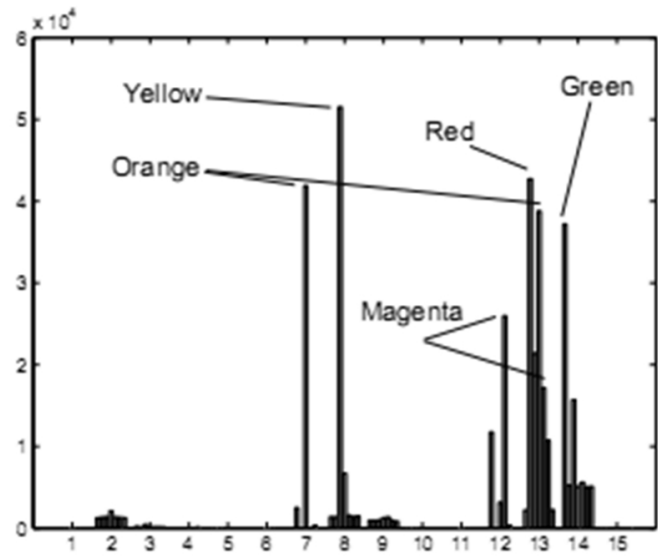

Figure 7: Average of histograms of the tested colors

The Ping-Pong is classified as:

Green if:

bl $14>10000 \& b l 8<10000 \& b l 14>b l 13$ [13]

The last two conditions are used because the yellow color has a big component in the 14 block too.

Red if:

bl $13>10000 \&(b l 7 \& b l 8 \& b l 12)<10000$

The last condition prevents de system to classify an orange, yellow or magenta Ping-Pong as red.

Yellow if:

$$
(b l 7 \& b l 13)>10000
$$

Orange if:

$$
(\text { bl } 8 \& \text { bl 13) }>10000
$$

And Magenta if:

$$
(\text { bl } 12 \& \text { bl 13) }>10000
$$

where $b l i$ indicates the $i$-counter value.

The results obtained are shown in the confusion matrix in Table 3. As can be observed from Table 3, the magenta color is confused with the red one and vice versa. The percentage of true positives is $95.2 \%$; therefore, the classification error is $4.8 \%$. Unlike green, yellow, and orange colors whose histograms are very different to the others, magenta and red colors tend to confuse due to two main reasons. First one is that some red
Table 2. Blocks modified by each color

\begin{tabular}{cc}
\hline Color & Blocks \\
\hline Green & 14 \\
Red & 13 \\
Yellow & 8 \\
Orange & 7,13 \\
Magenta & 12,13
\end{tabular}

Ping-Pongs showed a big component in block 12, appearing to the system like magenta. Second one is that some magenta Ping-Pongs have a bigger component in the block 13 than in 12 leading to misclassification. The undetections and some misclassifications occur because some Ping-Pongs deviate during the fall, increasing the distance to the camera, appearing smaller in the image and therefore reducing the value of the maxima.

Table 3. Sorting experiment results

\begin{tabular}{lcccccc}
\hline & \multicolumn{5}{c}{ Classified Color } \\
Color & Green & Red & Yellow & Orange & Magenta & Undetected \\
\hline Green & 96 & & & & 4 & 4 \\
Red & & 95 & & & 4 & 1 \\
Yellow & & & 99 & & & 1 \\
Orange & & & & 100 & & \\
Magenta & 7 & & & 86 & 7 \\
\hline
\end{tabular}

\section{CONCLUSION}

This article showed architecture for the implementation of the SCT on FPGA. Also, it was shown that real-time classification of objects by color using FPGA is possible. The key for the real-time performance is the possibility of computing 16 or more histograms in parallel with a concurrent circuit, in opposition to the processor solution that can not accomplish such a task. Besides, the structure allows us to analyze multiple views of the same scene by adding cameras and instances of the circuit as needed, keeping the execution time unaffected. The size of the object can be computed too, getting more information with the same performance. Achieving a faster performance, computing more characteristics of the objects, using coffee beans and analyzing more views are some of the problems that have to be faced in future work. 


\section{ACKNOWLEDGMENT}

The authors would like to thank DIMA (Dirección de Investigación Manizales), Facultad de Ingeniería y Arquitectura, Departamento de Ingeniería Eléctrica, Electrónica y Computación of the Universidad Nacional de Colombia Sede Manizales and Facultad de Ingenierías, Departamento de Sistemas e Informática of the Universidad de Caldas. This work is supported by the DIMA through projects 13740 and 12475.

\section{BIBLIOGRAPHY}

1. Martínez, A., Gaskin, B., y Llanes, O. "Pronóstico para la Cosecha Selectiva del Café por Vibración". En Revista Ciencias Técnicas Agropecuarias, 2004; 13(2),1-4.

2. Aristizábal, I. D., Oliveros, C. E., y Álvarez, F. "Cosecha Mecánica del Café mediante Vibraciones Multidireccionales”. En Cenicafé, 1999; 50(3),173-181.

3. Aristizábal, I. D., Oliveros, C. E., y Álvarez, F. "Propiedades Físico-Mecánicas del Árbol de Café y su Relación con la Mecanización de la Cosecha”. En Cenicafé, 1999; 50(4),313-326.

4. Sanz Uribe, J., Oliveros Tascón, C., y Cardona Duque, J. "Sistema de clasificación y selección de frutos por color". En Gaceta de Prpopiedad Industrial , 2008; 599 (07 128.272), 486.

5. Maya, C. "Desarrollo de Algoritmos para la Caracterización y Clasificación de Granos de Café". Manizales: Universidad Nacional de Colombia, 2001.

6. Sandoval, Z. "Caracterización y Clasificación de Frutos de Café usando Visión Artificial". Manizales: Universidad Nacional de Colombia. 2005.

7. Betancur, J., y Prieto, F. “Active Contour-Basesd Segmentation of Coffee Cherries Images”. En Proceedings of International Conference on Signal Processing 2008, 2008; 2738-2741.

8. Bustamante Giraldo, A. "Prototipo para la Selección Automática de Café en Cereza". Manizales: Universidad Nacional de Colombia. 2004.

9. Ruiz Altisent, M., Ruiz García, L., Moreda, G., Lu, R., y Hernández Sánchez, N. "Sensors for product characterization and quality of specialty crops - A review". En Computers and Electronics in Agriculture, 2010; 74(2), 176-194.

10. Gómez, E. "Caracterización de frutos maduros de café mediante visión artificial". Manizales: Universidad Nacional de Colombia, 2000.

11. Montes, N. "Segmentación de Imágenes de Frutos de Café en el Proceso de Beneficio". Manizales: Universidad Nacional de Colombia. 2003.

12. Umbaugh, S. E. Computer Vision and Image Processing: A Practical Approach Using CVIPTools. Upper Saddle River, NJ: Prentice Hall PTR. 1997. 